\title{
Health-related quality of life outcomes in complex adult spinal deformity surgery
}

\author{
Max S. Riley, BA, ${ }^{1}$ Keith H. Bridwell, MD, ${ }^{1}$ Lawrence G. Lenke, MD, ${ }^{2}$ Jonathan Dalton, BA, ${ }^{1}$ and \\ Michael P. Kelly, MD'
}

\begin{abstract}
1Department of Orthopedic Surgery, Washington University School of Medicine, St. Louis, Missouri; and 'Department of Orthopedic Surgery, Columbia University College of Physicians and Surgeons, New York, New York
\end{abstract}

\begin{abstract}
OBJECTIVE Significant health-related quality of life (HRQOL) benefits have been observed for patients undergoing primary and revision adult spinal deformity (ASD) surgery. The purpose of this study was to report changes in HRQOL measures in a consecutive series of patients undergoing complex spinal reconstructive surgery, using Scoli-RISK-1 (SR-1) inclusion criteria.
\end{abstract}
METHODS This was a single-center, retrospective cohort study. The SR- 1 inclusion criteria were used to define patients with complex ASD treated between June 1, 2009, and June 1, 2011. Standard preoperative and perioperative data were collected, including the Scoliosis Research Society (SRS)-22r instrument. The HRQOL changes were evaluated at a minimum 2-year follow-up. Standardized forms were used to collect surgery-related complications data for all patients. Complications were defined as minor, transient major, or permanent major. Patients who achieved a minimum 2-year follow-up were included in the analysis.

RESULTS Eighty-four patients meeting SR-1 criteria were identified. Baseline demographic and surgical data were available for $74 / 84(88 \%)$ patients. Forty-seven of $74(64 \%)$ patients met the additional HRQOL criteria with a minimum 2-year follow-up (mean follow-up 3.4 years, range 2-6.5 years). Twenty-one percent of patients underwent posterior fusion only, $40 \%$ of patients had a posterior column osteotomy, and $38 \%$ had a 3 -column osteotomy. Seventy-five percent of patients underwent a revision procedure. Significant improvements were observed in all SRS-22r domains: Pain: +0.8 $(p<0.001)$; Self-Image: +1.4 ( $p<0.001)$; Function: $+0.46(p<0.001)$; Satisfaction: $+1.6(p<0.001)$; and Mental Health: $+0.28(p=0.04)$. With the exception of Mental Health, more than $50 \%$ of patients achieved a minimum clinically important difference (MCID) in SRS-22r domain scores (Mental Health: 20/47, 42.6\%). A total of 65 complications occurred in 31 patients. This includes $29.8 \%$ (14/47) of patients who suffered a major complication and $17 \%(8 / 47)$ who suffered a postoperative neurological deficit, most commonly at the root level $(10.6 \%, 5 / 47)$. Of the 8 patients who suffered a neurological deficit, 1 (13\%) was able to achieve MCID in the SRS Function domain.

CONCLUSIONS The majority of patients experienced clinically relevant improvement in SRS-22r HRQOL scores after complex ASD surgery. The greatest improvements were seen in the SRS Pain and SRS Self-Image domains. Although $30 \%$ of patients suffered a major or permanent complication, benefits from surgery were still attained. Patients sustaining a neurological deficit or major complication were unlikely to achieve HRQOL improvements meeting or exceeding MCID for the SRS Function domain.

https://thejns.org/doi/abs/10.3171/2017.6.SPINE17357

KEY WORDS adult spinal deformity; scoliosis; osteotomy; subtraction; outcomes; complex; Scoli-RISK-1

A DULT spinal deformity (ASD) surgeries are associated with high complication rates, including new neurological deficits. ${ }^{7-9,11,12,16}$ Complication rates exceeding $70 \%$ have recently been reported. ${ }^{27}$ In addition to medical complications, the most complex deformities are associated with high neurological risks. Recent prospective studies of complex ASD surgeries have reported new neurological deficit rates of approximately $20 \%$. $^{23,26}$ Despite these risks, the number of spinal deformity surgeries performed yearly is increasing. ${ }^{13,15}$ Given the inherent risk associated with these complex procedures, a benefit from surgery must be achieved. In a value-driven health care economy, the benefits of complex ASD surgeries will need to be defined.

ABBREVIATIONS ASD = adult spinal deformity; HRQOL = health-related quality of life; IOM = intraoperative neurophysiological monitoring; $M C I D=$ minimum clinically important difference; SR-1 = Scoli-RISK-1; SRS = Scoliosis Research Society; 3-CO = 3-column osteotomy.

SUBMITTED March 24, 2017. ACCEPTED June 7, 2017

INCLUDE WHEN CITING Published online November 24, 2017; DOI: 10.3171/2017.6.SPINE17357. 
There is a paucity of health-related quality of life (HRQOL) data related to complex ASD surgery. Several large, prospective, multicenter database studies have reported outcomes of ASD, with coronal and sagittal plane deformities defining ASD. 1,4,6,18,20,22,23,25,27-29 Embedded within these cohorts are patients undergoing the highestrisk surgeries, with 3-column osteotomies (3-COs) and preexisting spinal cord deficits such as myelopathy. In general, HRQOL improvements are attained after these surgeries. However, complications are known to negatively affect HRQOL scores, particularly if the complication results in a permanent condition..$^{19}$ Complex ASD surgeries are associated with the highest risk for these types of complications.

The purpose of this study was to examine the effect of surgery for complex ASD on HRQOL scores from a single center at a minimum 2-year follow-up. We hypothesized that surgery would offer benefits to the majority of patients, in the setting of high complication rates. Furthermore, we expected that "recoverable" complications would not have a negative effect, whereas permanent conditions would negatively affect HRQOL.

\section{Methods \\ Patient Selection}

After institutional review board approval, patients treated for ASD between June 1, 2009, and June 1, 2011, were identified in the surgical registry of a single center. Patient consent was not required. The inclusion criteria were adopted from the Scoli-RISK-1 (SR-1) study, defining complex ASD (Table 1). Only patients with completed preoperative Scoliosis Research Society (SRS)-22r questionnaires and minimum 2-year follow-up with completed SRS-22r questionnaires were included in the analysis. Patients were excluded if they had a history of recent substance dependency, psychosocial disturbance (e.g., schizophrenia), active malignancy, active bacterial infection (systemic or local), recent trauma (within 3 months), prior paraplegia, or were pregnant or nursing.

Surgeries were performed by 1 of 3 fellowship-trained spine surgeons. The procedures were tailored to the needs of the patient and at the discretion of the attending surgeon. Antifibrinolytic therapy was used during surgery, except when contraindicated by a prior venothromboembolic event, impaired renal function, or a history of color blindness. In all cases, intraoperative neurophysiological monitoring (IOM) with somatosensory evoked potentials, descending neurogenic evoked potentials, and electromyography was used. In the absence of reliable IOM, intraoperative Stagnara tests were performed. All patients underwent a neurological examination prior to extubation.

\section{Data Collection}

Standardized data collection sheets were used to collect demographic, radiographic, and perioperative data. Demographic data collected included age, sex, race, body mass index, primary diagnosis, and any prior history of spine surgery. Standard radiographic variables were measured preoperatively and at a minimum 2-year follow-up. Coronal measurements included maximum coronal Cobb
TABLE 1. Scoli-RISK-1 inclusion criteria

\begin{tabular}{l} 
Age 18-80 yrs \\
Primary scoliosis, kyphosis, or kyphoscoliosis, w/ major Cobb angle \\
$\geq 80^{\circ}$ \\
Congenital spinal deformity undergoing reconstruction w/ any oste- \\
otomy \\
Revision spinal deformity undergoing reconstruction w/ any osteotomy \\
\hline Any patient undergoing a 3-CO \\
Any patient w/ myelopathy due to the spinal deformity \\
Any patient w/ ossification of the ligamentum flavum or posterior longi- \\
tudinal ligament, \& undergoing a reconstruction w/ decompression \\
\hline
\end{tabular}

angle and C-7 alignment (magnitude and direction). Sagittal measurements included major sagittal Cobb angle, thoracic kyphosis Cobb angle (T5-12), lumbar lordosis Cobb angle (T12-S1), pelvic incidence, sacral slope, and C-7 sagittal vertical axis. Perioperative data collected included whether the surgery was a revision, the type of osteotomy performed, intraoperative neurological deficit, operating time, estimated blood loss, and any postoperative complications. Complications were classified as minor and major, according to the system proposed by Glassman et al. ${ }^{19}$

The primary outcome for this study was the HRQOL score collected via the SRS-22r questionnaire. ${ }^{2,5}$ The mean differences in preoperative and minimum 2-year follow-up SRS scores were calculated for each domain. Individual patients' improvement in each SRS domain was calculated and compared with a minimum clinically important difference (MCID) reference value. The MCID values were defined as SRS Pain (0.4), SRS Self-Image (0.8), SRS Function (0.4), SRS Mental Health (0.4), and SRS Subscore (0.4). ${ }^{10}$

\section{Statistical Analysis}

Frequency distributions and summary statistics were calculated for all variables. Paired samples t-tests were used to compare pre- and postoperative radiographic parameters. Wilcoxon signed-rank tests were used to compare paired pre- and postoperative HRQOL, and the Wilcoxon rank-sum test was used to compare groups according to complication occurrence. The independent samples t-test was used to compare continuous data between included groups and those lost to follow-up. The chi-square test was used to compare demographic and perioperative rates between included groups and those lost to follow-up. The HRQOL difference scores for each patient were compared with the MCID to determine if a clinically significant difference had been achieved. The HRQOL changes were analyzed by complication type (none/minor/major/permanent) and by neurological deficit (no deficit/root/spinal cord). Statistical significance was defined as $\mathrm{p}<0.05$; SPSS version 24 software (IBM, Inc.) was used for all analyses.

\section{Results \\ Descriptive Data}

Using the SR-1 criteria, 84 patients were identified as 
TABLE 2. Preoperative demographic data in 74 patients with complex ASD surgery

\begin{tabular}{lccc}
\hline \multicolumn{1}{c}{ Variable } & Included, $\mathrm{n}=47$ & Lost to FU, $\mathrm{n}=27$ & $\mathrm{p}$ Value \\
\hline Age in yrs & $50.7 \pm 16$ & $47.4 \pm 18$ & 0.42 \\
\hline Female sex & $33(70.2)$ & $20(74.1)$ & 0.72 \\
\hline BMI & $30 \pm 6.3$ & $27 \pm 8$ & 0.08 \\
\hline Nicotine use & $2(4.3)$ & $8(29.6)$ & 0.002 \\
\hline No preop neuro deficit & $41(87.2)$ & $19(70.4)$ & 0.08 \\
\hline Revision procedure & $35(74.5)$ & $18(66.7)$ & 0.47 \\
\hline ASA score & & & 0.19 \\
\hline 1 & $0(0)$ & $1(3.7)$ & \\
\hline 2 & $34(75.6)$ & $16(59.3)$ & \\
\hline 3 & $11(24.4)$ & $9(33.3)$ & \\
\hline 4 & $0(0)$ & $0(0)$ & \\
\hline Missing & $2(4.3)$ & $1(3.7)$ & \\
\hline
\end{tabular}

$\mathrm{ASA}=$ American Society of Anesthesiologists; $\mathrm{BMI}=$ body mass index; FU = follow-up; neuro = neurological.

Values expressed as no. of patients (\%) or mean \pm SD.

having undergone complex ASD surgery between 2009 and 2011. Demographic and surgical data were available for $74(88 \%)$ of these patients. Baseline and minimum 2-year follow-up radiographic and HRQOL data were available for $47 / 74$ (64\%) patients. Of these, 33 (70.2\%) were female and $14(29.8 \%)$ were male. The majority of patients underwent an osteotomy (37/47, 79\%). The average follow-up was 3.4 years (range 2-6.5 years). Baseline demographic data for all patients are summarized in Table 2 , including those lost to follow-up.

Table 3 summarizes the perioperative data collected for all patients. The majority of patients $(40 / 47,85 \%)$ underwent a single-stage procedure. A total of 65 perioperative complications occurred in 31 patients. Excessive bleeding was the most common complication overall $(18 / 65,27.7 \%)$. A majority of patients had at least 1 medical complication postoperatively (68.1\%), and $17 \%$ experienced postoperative neurological deficits. Of those lost to follow-up, 7.4\% $(2 / 27)$ experienced postoperative neurological deficits. The majority of deficits were at the root level (spinal cord: 3/47, 6.4\%; root: 5/47, 10.6\%; cauda equina: $0 / 47,0 \%$ ). Three patients sustained permanent, major complications: 2 with neurological deficits at the spinal cord level, and 1 with deep wound infection.

\section{Outcome Data}

There was a significant improvement in both coronal and sagittal major Cobb angles, sagittal alignment, and lumbar lordosis at 2-year follow-up (Table 4). There was no significant change in coronal alignment or thoracic kyphosis (T5-12). The HRQOL outcome measures are presented in Table 5. The SRS-22r scores across all domains showed significant increases. The HRQOL increases were stable at the 1-year and latest follow-up time points. The greatest improvements were seen in the SRS Self-Image $(+1.4, \mathrm{p}<0.001)$ and SRS Satisfaction $(+1.6, \mathrm{p}<0.001)$ domains. The majority of patients experienced clinically significant improvements in all domains, with the excep-
TABLE 3. Perioperative data in 74 patients with complex ASD surgery

\begin{tabular}{|c|c|c|c|}
\hline Variable & $\begin{array}{c}\text { Included, } \\
n=47\end{array}$ & $\begin{array}{c}\text { Lost to FU, } \\
n=27\end{array}$ & $\begin{array}{c}p \\
\text { Value }\end{array}$ \\
\hline Osteotomy type & & & 0.65 \\
\hline None & $10(21.3)$ & $5(18.5)$ & \\
\hline PCO & $19(40.4)$ & $8(29.6)$ & \\
\hline PSO & $12(25.5)$ & $8(29.6)$ & \\
\hline VCR & $6(12.8)$ & $6(22.2)$ & \\
\hline Staged procedure & & & 0.34 \\
\hline Yes & $7(14.9)$ & $2(7.4)$ & \\
\hline \multicolumn{4}{|l|}{ Stage 1} \\
\hline No. & $46(97.9)$ & $27(100)$ & \\
\hline Op time, min & $469.2 \pm 99.4$ & $469.7 \pm 111.5$ & 0.98 \\
\hline Mean EBL \pm SE, ml & $1974.5 \pm 208.2$ & $1857.6 \pm 234.3$ & 0.72 \\
\hline \multicolumn{4}{|l|}{ Stage 2} \\
\hline No. & $3(6.4)$ & $2(7.4)$ & \\
\hline Op time, $\min$ & $309.3 \pm 71.7$ & $273.5 \pm 85.6$ & 0.64 \\
\hline Mean EBL \pm SE, ml & $1166.7 \pm 768.8$ & $1250 \pm 250$ & 0.94 \\
\hline \multicolumn{4}{|c|}{ Stage 3} \\
\hline No. & $1(2.1)$ & $0(0)$ & \\
\hline Op time, min & 245 & 0 & \\
\hline Mean EBL, ml & 500 & 0 & \\
\hline Fusion levels & $12.5 \pm 3.7$ & $13.6 \pm 3.9$ & 0.23 \\
\hline Any medical complication & & & 0.81 \\
\hline Yes & 32 (68.1) & $17(63.0)$ & \\
\hline Postop neuro deficit & & & 0.55 \\
\hline Root level & $5(10.6)$ & $1(4)$ & \\
\hline Cauda equina syndrome & $0(0)$ & $0(0)$ & \\
\hline Spinal cord level & $3(6.4)$ & $1(4)$ & \\
\hline Mean follow-up in yrs & $3.4 \pm 1.3$ & NA & \\
\hline
\end{tabular}

$\mathrm{EBL}=$ estimated blood loss; $\mathrm{NA}=$ not available; $\mathrm{PCO}=$ posterior column osteotomy; $\mathrm{PSO}=$ pedicle subtraction osteotomy; $\mathrm{VCR}$ = vertebral column resection.

Unless otherwise specified, the values are expressed as no. of patients (\%) or mean \pm SD.

tion of SRS Mental Health (SRS Pain: 32/47, 68.1\%; SRS Self-Image: 37/47, 78.7\%; SRS Function: 27/47, 57.4\%; SRS Mental Health: 20/47, 42.6\%). Of the 27 patients lost to follow-up, $23(85.2 \%)$ had baseline HRQOL data, and $8(29.6 \%)$ had available 1-year HRQOL data. No statistically significant HRQOL differences were observed at the baseline or 1-year time points between the included group and those lost to follow-up.

Tables 6 and 7 describe changes in HRQOL values by complication type and neurological deficit. Patients who suffered any temporary major complication experienced less improvement in SRS Pain than patients with no complications $(+0.12, \mathrm{p}=0.03)$. Patients with postoperative root-level deficits had less improvement in SRS Function than patients who suffered no neurological deficit $(-0.11$, $\mathrm{p}=0.03$ ). Two patients sustained permanent neurological deficits at the spinal cord level; both deficits were classified as ASIA (American Spinal Injury Association) 
TABLE 4. Preoperative and postoperative radiographic data in patients with complex ASD surgery

\begin{tabular}{|c|c|c|}
\hline Variable & Mean \pm SD & $\mathrm{p}$ Value \\
\hline \multicolumn{3}{|c|}{ Major coronal Cobb angle } \\
\hline Baseline & $49.5^{\circ} \pm 29.2^{\circ}$ & \\
\hline Postop & $26.7^{\circ} \pm 20^{\circ}$ & $<0.001$ \\
\hline \multicolumn{3}{|l|}{ Coronal balance, $\mathrm{mm}$} \\
\hline Baseline & $29.1 \pm 24.6$ & \\
\hline Postop & $21.2 \pm 17.4$ & 0.09 \\
\hline \multicolumn{3}{|c|}{ Major sagittal Cobb angle } \\
\hline Baseline & $50.5^{\circ} \pm 37.8^{\circ}$ & \\
\hline Postop & $33.1^{\circ} \pm 28.2^{\circ}$ & $<0.001$ \\
\hline \multicolumn{3}{|c|}{ Thoracic kyphosis (T5-12) } \\
\hline Baseline & $38^{\circ} \pm 24.4^{\circ}$ & \\
\hline Postop & $35^{\circ} \pm 16.6^{\circ}$ & 0.28 \\
\hline \multicolumn{3}{|c|}{ Lumbar lordosis (T12-S1) } \\
\hline Baseline & $38.3^{\circ} \pm 22.6^{\circ}$ & \\
\hline Postop & $44.9^{\circ} \pm 14.7^{\circ}$ & 0.001 \\
\hline \multicolumn{3}{|l|}{ Pelvic incidence } \\
\hline Baseline & $52.6^{\circ} \pm 17.1^{\circ}$ & \\
\hline Postop & $52.9^{\circ} \pm 13.6^{\circ}$ & 0.95 \\
\hline \multicolumn{3}{|l|}{ Sacral slope } \\
\hline Baseline & $27.8^{\circ} \pm 13.9^{\circ}$ & \\
\hline Postop & $31.1^{\circ} \pm 9.9^{\circ}$ & 0.01 \\
\hline \multicolumn{3}{|c|}{ Sagittal alignment (C-7 SVA), mm } \\
\hline Baseline & $96.4 \pm 75.2$ & \\
\hline Postop & $44.2 \pm 34.9$ & $<0.001$ \\
\hline
\end{tabular}

SVA = sagittal vertical axis

Grade D. Both patients experienced improvements in SRS Pain $(+0.8$ in one, +1.4 in the other) and SRS Self-Image (+0.9 in one, +2.9 in the other). One patient had a globally weak ( $4 / 5$ strength) right lower extremity with a worse SRS Function score (-0.6). One patient had bilateral foot drops ( $3 / 5$ bilateral tibialis anterior) without worsening of function (+0.6). One patient with a transient right-sided root-level deficit had worse pain scores at last follow-up $(-1.6)$. Patients sustaining a neurological deficit or major complication were unlikely to achieve HRQOL improvements of, or exceeding, the MCID for SRS Function (none: 67\%; major complication: 36\%; neurological deficit: $13 \%$ ).
Despite major complications and neurological deficits, improvements in SRS Pain (none: 80\%; major complication: 57\%; neurological deficit: 75\%) and SRS Self-Image (none: 67\%; major complication: 93\%; neurological deficit: $100 \%$ ) reaching the MCID level were common.

No significant differences in HRQOL improvement were observed between patients who underwent 3-COs $(n=18)$ and those who did not $(n=29)$. For each group, patients achieved significant improvement in all domains except SRS Mental Health (no 3-CO: +0.27 [p = 0.16]; 3-CO: $+0.28[\mathrm{p}=0.11])$. Patients not undergoing a 3-CO suffered a total of 34 complications, compared with 31 complications in the 3-CO group. We did not observe a significant difference between groups with respect to any complication rate (no 3-CO: 62.1\%; 3-CO: 77.8\% [p $=0.27]$ ), major complication rate (no 3-CO: $31 \%$; 3-CO: $27.8 \%$ [p $=0.98]$ ), or postoperative neurological deficit rate (no 3-CO: 17.2\%; 3-CO: 16.7\% [p = 0.96]).

\section{Discussion}

As the population ages, the rate of surgeries performed for ASD will increase. . $^{13,15}$ Advances in technique, instrumentation, and perioperative care have allowed these surgeries to become increasingly complex. These complex procedures are associated with a concomitantly increased risk of complication. ${ }^{14}$ Numerous studies have indicated improvement in pain, function, and HRQOL measures after ASD surgery. 1,4,6,18,20,22,25,27-29 No study has reported HRQOL outcomes after complex spinal deformity surgery according to the SR-1 definition for complex surgery. ${ }^{23}$ The purpose of this study was to analyze changes in HRQOL patient outcome measures for a consecutive series of patients treated for complex spinal deformity and to evaluate the effect of complications on outcomes at a minimum 2-year follow-up.

We identified 47 patients with complex deformities and a minimum 2-year follow-up. Significant corrections of major coronal and sagittal Cobb angles, and of sagittal alignment were obtained. Improvements across all HRQOL domains (SRS Pain, SRS Self-Image, SRS Function, SRS Satisfaction, and SRS Mental Health) and SRS Subscore were found at an average of 3.4 years' follow-up. The greatest improvements were seen in the SRS SelfImage $(+1.4, \mathrm{p}<0.001)$ and SRS Satisfaction $(+1.6, \mathrm{p}<$ 0.001 ) domains. The least improvement was seen in the SRS Mental Health domain $(+0.28, p=0.04)$. No significant differences in HRQOL improvement were observed

TABLE 5. Comparison of baseline and minimum 2-year follow-up HRQOL parameters in 47 patients with complex ASD surgery

\begin{tabular}{lcccrcr}
\hline \multicolumn{1}{c}{ Variable } & \multicolumn{1}{c}{ Pain } & Self-Image & Function & Satisfaction & Mental Health & Subscore \\
\hline Baseline & $2.8 \pm 0.9$ & $2.3 \pm 0.7$ & $2.9 \pm 0.9$ & $2.8 \pm 1.2$ & $3.6 \pm 0.8$ & $2.9 \pm 0.7$ \\
\hline 1-yr FU & $3.5 \pm 0.9$ & $3.8 \pm 0.7$ & $3.2 \pm 0.9$ & $4.2 \pm 0.9$ & $3.9 \pm 0.7$ & $3.6 \pm 0.7$ \\
\hline Latest FU & $3.6 \pm 0.9$ & $3.7 \pm 0.8$ & $3.3 \pm 0.9$ & $4.4 \pm 0.8$ & $3.8 \pm 0.8$ & $3.6 \pm 0.7$ \\
\hline Mean improvement & $+0.8 \pm 1.1$ & $+1.4 \pm 0.8$ & $+0.46 \pm 0.8$ & $+1.6 \pm 1.5$ & $+0.28 \pm 0.8$ & $+0.74 \pm 0.7$ \\
\hline \% above MCID (no.) & $68.1 \%(32)$ & $78.7 \%(37)$ & $57.4 \%(27)$ & NA & $42.6 \%(20)$ & $74.5 \%(35)$ \\
\hline
\end{tabular}

Unless otherwise specified, the values are expressed as the mean \pm SD. The $p$ values for mean improvement were as follows: $p<0.001$ for Pain, Self-Image, Function, Satisfaction, and Subscore; $p=0.04$ for Mental Health. 
TABLE 6. The HRQOL changes by complication type in patients with complex ASD surgery

\begin{tabular}{lcccc}
\hline HRQOL & \multicolumn{3}{c}{ Complications \& Changes in SRS-22r Score (mean \pm SD) } \\
\cline { 2 - 5 } Domain & None, $\mathrm{n}=15$ & Any Minor, $\mathrm{n}=17$ & Any Major, $\mathrm{n}=11$ & Permanent, $\mathrm{n}=3$ \\
\hline Pain & $1.2 \pm 1.1^{*}$ & $0.83 \pm 1.1^{*}$ & $0.12 \pm 1.2 \dagger$ & $1.0 \pm 0.35$ \\
\hline Self-Image & $1.4 \pm 1.0^{*}$ & $1.3 \pm 0.74^{*}$ & $1.5 \pm 0.72^{*}$ & $1.6 \pm 1.1$ \\
\hline Function & $0.67 \pm 0.7^{*}$ & $0.65 \pm 0.87^{*}$ & $0.07 \pm 0.8$ & $0.0 \pm 0.6$ \\
\hline Satisfaction & $1.5 \pm 1.4^{*}$ & $1.7 \pm 1.4^{*}$ & $1.9 \pm 1.5^{*}$ & $0.5 \pm 2.6$ \\
\hline Mental Health & $0.31 \pm 0.93$ & $0.44 \pm 0.84$ & $0.02 \pm 0.76$ & $0.07 \pm 1.0$ \\
\hline Subscore & $0.87 \pm 0.77^{*}$ & $0.84 \pm 0.71^{*}$ & $0.45 \pm 0.69$ & $0.70 \pm 0.7$ \\
\hline
\end{tabular}

* Wilcoxon signed-rank test $p<0.05$ comparing pre- and postoperative means according to complication group.

$\dagger$ Wilcoxon rank-sum test $p<0.05$ comparing "None" as reference group.

between patients who underwent 3-CO procedures and those who did not. More than $50 \%$ of patients achieved the MCID or greater for all domains except SRS Mental Health $(20 / 47,42.6 \%)$. The greatest MCID achievement rates were seen in the SRS Self-Image $(37 / 47,78.7 \%)$ and SRS Pain $(32 / 47,68.1 \%)$ domains.

Bridwell et al. reported results of a prospective cohort study of patients with de novo adult symptomatic lumbar scoliosis. ${ }^{6}$ Surgery was associated with significant increases in the SRS Subscore, although no analysis of the individual domain scores was offered. Smith et al. presented results from a prospective cohort study of patients with a wide range of ASD pathologies. ${ }^{27}$ Patients who were treated experienced significant improvement across all 5 SRS domains. Improvements in HRQOL scores associated with surgery are a common finding, although there are no studies in which the present a priori definition of complex spinal deformity has been used to assess the success of surgery in the setting of greater risk.

Complex spinal deformity surgeries are not uncommonly associated with major complications, including new neurological deficits. The SR-1 cohort reported a new neurological deficit rate of $22 \%{ }^{23}$ At 6-month followup, half of these new neurological deficits had improved. These findings might suggest that with adequate recovery and follow-up, HRQOL outcomes may not be negatively affected by new neurological deficits. This theory is sup-

TABLE 7. The HRQOL changes by neurological deficit in patients with complex ASD surgery

\begin{tabular}{lccc}
\hline \multirow{2}{*}{$\begin{array}{c}\text { HRQOL } \\
\text { Domain }\end{array}$} & $\begin{array}{c}\text { Deficits \& Changes in SRS-22r Score (mean } \pm \text { SD) } \\
n=39\end{array}$ & $\begin{array}{c}\text { Root Level, } \\
n=5\end{array}$ & $\begin{array}{c}\text { Spinal Cord, } \\
n=3\end{array}$ \\
\cline { 2 - 4 } Pain & $0.85 \pm 1.2^{*}$ & $0.55 \pm 1.3$ & $0.67 \pm 0.81$ \\
\hline Self-Image & $1.4 \pm 0.87^{*}$ & $1.5 \pm 0.37^{*}$ & $1.6 \pm 1.1$ \\
\hline Function & $0.59 \pm 0.81^{*}$ & $-0.11 \pm 0.30 \dagger$ & $-0.20 \pm 0.69$ \\
\hline Satisfaction & $1.6 \pm 1.4^{*}$ & $2.6 \pm 1.6^{*}$ & $0.33 \pm 2.5$ \\
\hline Mental Health & $0.29 \pm 0.86^{*}$ & $0.29 \pm 0.79$ & $0.0 \pm 1.0$ \\
\hline Subscore & $0.78 \pm 0.73^{*}$ & $0.62 \pm 0.55$ & $0.50 \pm 0.79$ \\
\hline
\end{tabular}

* Wilcoxon signed-rank test $p<0.05$ comparing pre- and postoperative means according to complication group.

$\dagger$ Wilcoxon rank-sum test $p<0.05$ comparing "No Deficit" as reference group. ported by Auerbach et al., who found that so-called recoverable major complications were not associated with poor results at 2 -year follow-up. ${ }^{3}$ These findings are distinctly different from those of Glassman et al., who found that major complications did negatively affect HRQOL. ${ }^{19} \mathrm{We}$ observed that patients with major complications had worse SRS Pain scores at 2-year follow-up than patients with no complications. Similarly, patients with root-level deficits reported less improvement in SRS Function scores than those without a new neurological deficit. This is probably due to residual lower-extremity weakness affecting walking or more vigorous physical activity. Temporary and permanent major complications were rare, and comparisons with other groups were not powered to detect differences. Our results, combined with those of Auerbach et al., reinforce the need for longer-term follow-up of patients with ASD who sustain complications. With adequate follow-up and more patients, definitive conclusions regarding the effect of recoverable complications are possible.

A large percentage of patients (74.5\%) included in the study were undergoing revision spine surgery. Kelly et al. reviewed a series of 94 patients with ASD undergoing repeat revision surgery, mainly to correct pseudarthroses or to treat a deep wound infection. ${ }^{22}$ They reported significant increases in HRQOL measures across all 5 domains, with the greatest improvement seen in SRS Satisfaction, SRS Pain, and SRS Self-Image. These findings suggest that patients with ASD who undergo multiple revisions benefit from surgery, despite the inherent risk of such procedures. The fact that patients with both primary and revision deformities were able to recover from these surgeries and the related complications is due, in part, to the high-volume nature of the hospital. The entire care team is experienced with the care of patients with complex ASD, with dedicated operating teams. Thus, early identification of complications was possible. This is true of IOM as well, where the surgeon, nursing staff, monitoring staff, and anesthesia team are prepared for alerts with loss of data. It is mandatory to have an experienced team to take care of these complicated cases, so that all personnel along the care pathway can identify complications and respond appropriately and quickly.

In this series, significant improvements in patient-reported HRQOL measures were observed across all SRS domains. Using the values of MCID derived by Crawford 
et al., individual improvement for the SRS Pain, SRS SelfImage, and SRS Function domains exceeded the MCID threshold, with more than $50 \%$ of patients achieving MCID. ${ }^{10}$ The achievement of "clinically" important improvement for most patients suggests a benefit for complex ASD surgery. However, one should note that the definition of MCID is that of HRQOL improvement deemed beneficial in the absence of extra cost or risk associated with the intervention. ${ }^{21}$ Complex ASD surgeries are among the costliest and riskiest procedures performed. Therefore, a goal of exceeding, rather than meeting, MCID may be warranted. Further research defining the substantial clinical benefit for these patients is required.

This study is limited by the retrospective, single-center design and the lack of a nonoperative comparison cohort. Because this was a single-center study, these results may not be generalizable to other centers. Additionally, these results probably apply to complex ASD only; we did not examine common diseases, such as de novo adult lumbar scoliosis. Furthermore, we are probably underpowered to detect differences in HRQOL scores across complication groups, including neurological deficits. It is inappropriate to claim that new neurological deficits are not associated with worse outcomes based on our results. A larger cohort is required to describe the effect of new neurological deficits on HRQOL in patients with ASD.

Retrospective studies are subject to recall bias, although HRQOL data were collected at pre- and postoperative visits. In addition, retrospective cohort studies are limited by the information that is available in the chart upon review, which may underestimate complications such as new neurological deficits. ${ }^{24}$ This study is compromised by a $36 \%$ rate of loss to follow-up. Such a high rate might skew the patient-reported outcomes to overestimate or underestimate the true HRQOL improvement. However, we did not observe a significant HRQOL difference between included and excluded groups at the baseline or 1-year time points. We have shown that those patients lost to follow-up are not substantially different from those who remained compliant with follow-up with respect to baseline data, with the exception of smoking. Whether their outcomes are similar is unknown. Nicotine-use histories may predispose patients to more complications, including nonunion and worse HRQOL. 17,30 Thus, we may overestimate the benefit of surgery and underestimate complication rates and the detrimental effect of complications. Finally, we have a minimum 2-year follow-up with a mean of 3.4 years, which is inadequate to assess the results and durability of ASD surgery. Complications related to proximal junctional kyphosis and pseudarthrosis occur at 5 years postoperatively and beyond, necessitating longer follow-up in these complex cases. ${ }^{22}$

\section{Conclusions}

Our results suggest that a majority of patients attain clinically relevant improvement in HRQOL after surgery. More than $50 \%$ of patients experienced domain score improvements exceeding the MCID for SRS Pain, SRS SelfImage, and SRS Function. Patients suffering major complications and new neurological deficits were less likely to achieve MCID for SRS Function, whereas MCID thresholds were often met for SRS Pain and SRS Self-Image. As the name suggests, the MCID represents a threshold for minimum improvement. Due to the risk and cost associated with these complex procedures, the threshold for clinically significant improvement may be greater. Ongoing research regarding substantial clinical benefit thresholds may provide a more useful measure for evaluating clinical outcomes after complex ASD surgery. The data presented here will provide valuable information for the shared decision-making process in these complex surgeries.

\section{References}

1. Adogwa O, Parker SL, Shau D, Mendelhall SK, Cheng J, Aaronson O, et al: Long-term outcomes of revision fusion for lumbar pseudarthrosis: clinical article. J Neurosurg Spine 15:393-398, 2011

2. Asher MA, Lai SM, Glattes RC, Burton DC, Alanay A, Bago J: Refinement of the SRS-22 Health-Related Quality of Life questionnaire Function domain. Spine (Phila Pa 1976) 31:593-597, 2006

3. Auerbach JD, Lenke LG, Bridwell KH, Sehn JK, Milby $\mathrm{AH}$, Bumpass D, et al: Major complications and comparison between 3-column osteotomy techniques in 105 consecutive spinal deformity procedures. Spine (Phila Pa 1976) 37:1198-1210, 2012

4. Bridwell KH, Baldus C, Berven S, Edwards C II, Glassman $\mathrm{S}$, Hamill C, et al: Changes in radiographic and clinical outcomes with primary treatment adult spinal deformity surgeries from two years to three- to five-years follow-up. Spine (Phila Pa 1976) 35:1849-1854, 2010

5. Bridwell KH, Berven S, Glassman S, Hamill C, Horton WC III, Lenke LG, et al: Is the SRS-22 instrument responsive to change in adult scoliosis patients having primary spinal deformity surgery? Spine (Phila Pa 1976) 32:2220-2225, 2007

6. Bridwell KH, Glassman S, Horton W, Shaffrey C, Schwab F, Zebala LP, et al: Does treatment (nonoperative and operative) improve the two-year quality of life in patients with adult symptomatic lumbar scoliosis: a prospective multicenter evidence-based medicine study. Spine (Phila Pa 1976) 34:2171-2178, 2009

7. Bridwell KH, Lewis SJ, Edwards C, Lenke LG, Iffrig TM, Berra A, et al: Complications and outcomes of pedicle subtraction osteotomies for fixed sagittal imbalance. Spine (Phila Pa 1976) 28:2093-2101, 2003

8. Buchowski JM, Bridwell KH, Lenke LG, Kuhns CA, Lehman RA Jr, Kim YJ, et al: Neurologic complications of lumbar pedicle subtraction osteotomy: a 10-year assessment. Spine (Phila Pa 1976) 32:2245-2252, 2007

9. Cho SK, Bridwell KH, Lenke LG, Yi JS, Pahys JM, Zebala LP, et al: Major complications in revision adult deformity surgery: risk factors and clinical outcomes with 2- to 7-year follow-up. Spine (Phila Pa 1976) 37:489-500, 2012

10. Crawford CH III, Glassman SD, Bridwell KH, Berven SH, Carreon LY: The minimum clinically important difference in SRS-22R total score, appearance, activity and pain domains after surgical treatment of adult spinal deformity. Spine (Phila Pa 1976) 40:377-381, 2015

11. Daubs MD, Lenke LG, Cheh G, Stobbs G, Bridwell KH: Adult spinal deformity surgery: complications and outcomes in patients over age 60. Spine (Phila Pa 1976) 32:22382244, 2007

12. DeWald CJ, Stanley T: Instrumentation-related complications of multilevel fusions for adult spinal deformity patients over age 65: surgical considerations and treatment options in patients with poor bone quality. Spine (Phila Pa 1976) 31 (19 Suppl):S144-S151, 2006 
13. Deyo RA, Gray DT, Kreuter W, Mirza S, Martin BI: United States trends in lumbar fusion surgery for degenerative conditions. Spine (Phila Pa 1976) 30:1441-1447, 2005

14. Deyo RA, Mirza SK, Martin BI: Error in trends, major medical complications, and charges associated with surgery for lumbar spinal stenosis in older adults. JAMA 306:1088, 2011

15. Deyo RA, Mirza SK, Martin BI, Kreuter W, Goodman DC, Jarvik JG: Trends, major medical complications, and charges associated with surgery for lumbar spinal stenosis in older adults. JAMA 303:1259-1265, 2010

16. Emami A, Deviren V, Berven S, Smith JA, Hu SS, Bradford DS: Outcome and complications of long fusions to the sacrum in adult spine deformity: Luque-Galveston, combined iliac and sacral screws, and sacral fixation. Spine (Phila Pa 1976) 27:776-786, 2002

17. Glassman SD, Anagnost SC, Parker A, Burke D, Johnson JR, Dimar JR: The effect of cigarette smoking and smoking cessation on spinal fusion. Spine (Phila Pa 1976) 25:26082615,2000

18. Glassman SD, Carreon LY, Shaffrey CI, Polly DW, Ondra SL, Berven SH, et al: The costs and benefits of nonoperative management for adult scoliosis. Spine (Phila Pa 1976) 35:578-582, 2010

19. Glassman SD, Hamill CL, Bridwell KH, Schwab FJ, Dimar JR, Lowe TG: The impact of perioperative complications on clinical outcome in adult deformity surgery. Spine (Phila Pa 1976) 32:2764-2770, 2007

20. Good CR, Lenke LG, Bridwell KH, O'Leary PT, Pichelmann MA, Keeler KA, et al: Can posterior-only surgery provide similar radiographic and clinical results as combined anterior (thoracotomy/thoracoabdominal)/posterior approaches for adult scoliosis? Spine (Phila Pa 1976) 35:210-218, 2010

21. Jaeschke R, Singer J, Guyatt GH: Measurement of health status. Ascertaining the minimal clinically important difference. Control Clin Trials 10:407-415, 1989

22. Kelly MP, Lenke LG, Bridwell KH, Agarwal R, Godzik J, Koester L: Fate of the adult revision spinal deformity patient: a single institution experience. Spine (Phila Pa 1976) 38:E1196-E1200, 2013

23. Lenke LG, Fehlings MG, Shaffrey CI, Cheung KMC, Carreon L, Dekutoski MB, et al: Neurologic Outcomes of Complex Adult Spinal Deformity Surgery: Results of the Prospective, Multicenter Scoli-RISK-1 Study. Spine (Phila Pa 1976) 41:204-212, 2016

24. Mantel N, Haenszel W: Statistical aspects of the analysis of data from retrospective studies of disease. J Natl Cancer Inst 22:719-748, 1959

25. Smith JS, Kasliwal MK, Crawford A, Shaffrey CI: Outcomes, expectations, and complications overview for the surgical treatment of adult and pediatric spinal deformity. Spine Deform [epub ahead of print], 2012

26. Smith JS, Klineberg E, Lafage V, Shaffrey CI, Schwab F, Lafage R, et al: Prospective multicenter assessment of perioperative and minimum 2-year postoperative complication rates associated with adult spinal deformity surgery. J Neurosurg Spine 25:1-14, 2016

27. Smith JS, Lafage V, Shaffrey CI, Schwab F, Lafage R, Hostin R, et al: Outcomes of operative and nonoperative treatment for adult spinal deformity: a prospective, multicenter, propensity-matched cohort assessment with minimum 2-year follow-up. Neurosurgery 78:851-861, 2016

28. Smith JS, Shaffrey CI, Berven S, Glassman S, Hamill C, Horton W, et al: Improvement of back pain with operative and nonoperative treatment in adults with scoliosis. Neurosurgery 65:86-94, 2009

29. Smith JS, Shaffrey CI, Berven S, Glassman S, Hamill C, Horton W, et al: Operative versus nonoperative treatment of leg pain in adults with scoliosis: a retrospective review of a prospective multicenter database with two-year follow-up. Spine (Phila Pa 1976) 34:1693-1698, 2009

30. Vogt MT, Hanscom B, Lauerman WC, Kang JD: Influence of smoking on the health status of spinal patients: the National Spine Network database. Spine (Phila Pa 1976) 27:313-319, 2002

\section{Disclosures}

Dr. Kelly receives support for a non-study-related clinical or research effort that he oversees from DePuy Synthes, Barnes Jewish Foundation, Orthopedic Research and Education Foundation (OREF), and Cervical Spine Research Society (CSRS). Dr. Lenke earns royalties from Medtronic, is a consultant for Medtronic, and receives support for a non-study-related clinical or research effort that he oversees from EOS Technology and Fox Family Foundation.

\section{Author Contributions}

Conception and design: Kelly, Riley. Acquisition of data: Kelly, Riley. Analysis and interpretation of data: all authors. Drafting the article: Kelly, Riley, Dalton. Critically revising the article: Kelly, Bridwell, Lenke, Dalton. Reviewed submitted version of manuscript: all authors.

\section{Correspondence}

Michael P. Kelly, Department of Orthopedic Surgery, Washington University School of Medicine, 660 South Euclid Ave., Box 8233, St. Louis, MO 63110. email: kellymi@wudosis.wustl.edu. 